\title{
Basal cell adenocarcinoma of the palate with squamous metaplasia
}

Suzana Orsini Machado de Sousa, Monica Schwarzschild, Ney Soares de Araújo, Vera Cavalcanti de Araújo

Abstract

Basal cell adenocarcinoma is a rare salivary gland tumour, especially in minor glands. The clinical, histological, and immunohistochemical features of a case involving the palate are described. Formalin fixed, paraffin embedded sections of the tumour were examined in haematoxylin and eosin (H\&E) sections and also using immunostaining for cytokeratins 7 , $8,13,14,18,19$, vimentin, muscle specific actin (HHF35), and laminin. H\&E sections showed that the tumour was composed mainly of basaloid cells and a

Table 1 Monoclonal antibodies

\begin{tabular}{llc}
\hline Types & Concentration & $\begin{array}{c}\text { Incubation time } \\
\text { (min) }\end{array}$ \\
\hline CK $7^{\star}$ & $1: 50$ & 60 \\
CK 8 & $1: 80$ & 30 \\
CK 13 & $1: 80$ & 120 \\
CK 14 & $1: 50$ & 30 \\
CK 18 & $1: 600$ & 60 \\
CK 19† & $1: 50$ & 60 \\
Vimentin $\dagger$ & $1: 75$ & 120 \\
HHF35 & $1: 150$ & 60 \\
Laminin & $1: 500$ & 120
\end{tabular}

*Supplier: Biogenex Lab., San Ramon, California, USA. †Supplier: Dako A/S, Glostrup, Denmark. CK, cytokeratin.

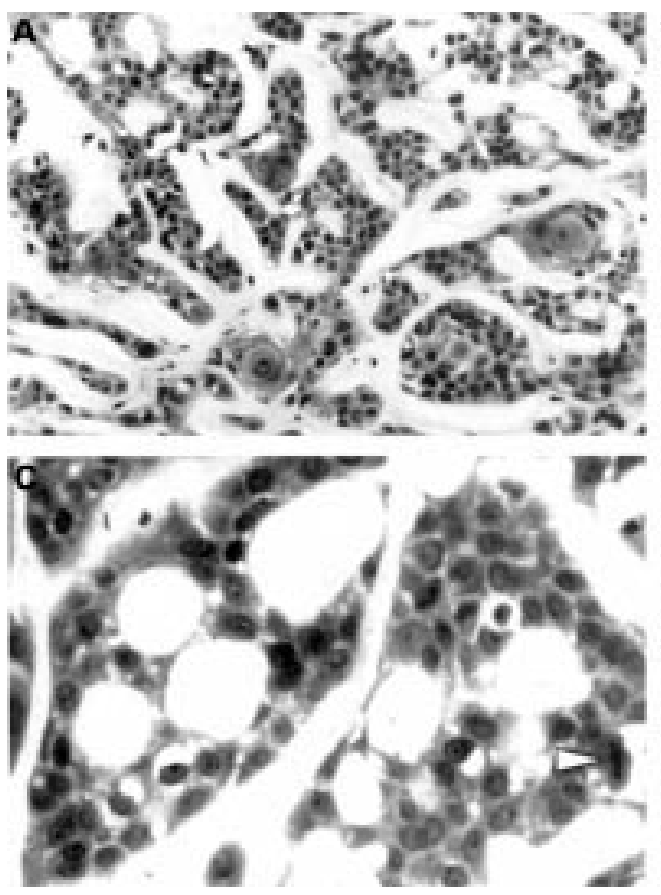

striking feature was the presence of squamous metaplasia. Neural invasion was also conspicuous. Immunohistochemical reactions indicated that cytokeratin 14 was expressed by all tumour cells and vimentin by all cells except those in the areas of squamous metaplasia. The remaining cytokeratins and actin were present in some of the tumour cells, while laminin showed discreet positivity around cell arrangements. The foci of squamous metaplasia and the immunohistochemical findings are helpful in distinguishing basal cell adenocarcinoma from other salivary gland tumours which show basaloid cells. (F Clin Pathol 2000;53:153-156)

Keywords: basal cell adenocarcinoma; salivary gland neoplasms

Basal cell adenocarcinoma is a rare salivary gland tumour which is considered to be the malignant counterpart of basal cell adenoma. Ellis and Wiscovitch ${ }^{1}$ have published the largest series of cases (29), and have defined the clinicopathological features. Basal cell adenocarcinoma is now universally recognised as a malignant salivary gland tumour and it is classified as
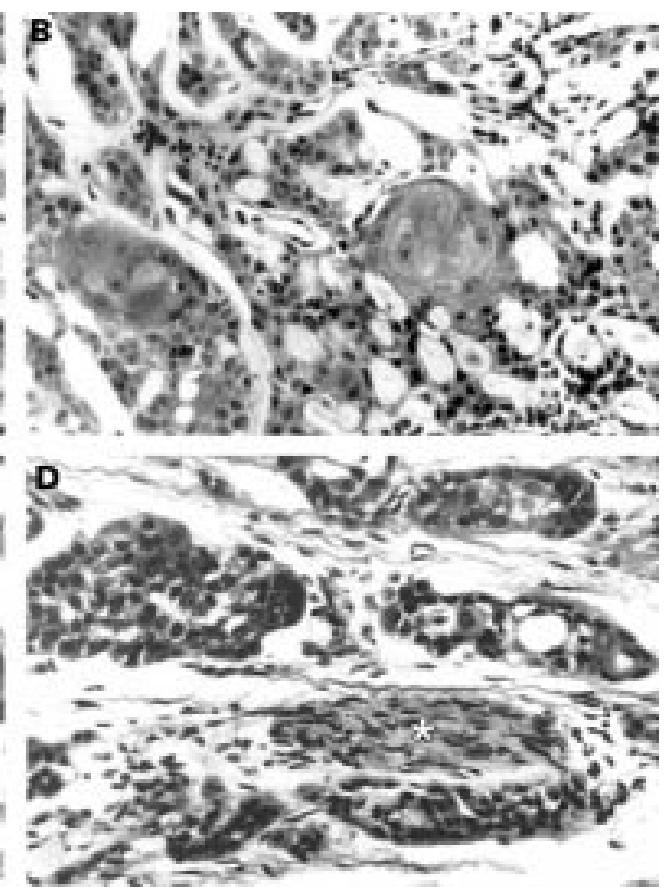

Department of Oral Pathology, School of Dentistry, University of São Paulo and

Fleury Laboratory, Av Prof Lineu Prestes 2227, 05508-900 São Paulo, SP, Brazil S O M de Sousa M Schwarzschild N S de Araújo V C de Araújo

Correspondence to: Professor de Sousa email scmsousa@fo.usp.br

Accepted for publication 13 September 1999
Figure 1 Haematoxylin and eosin stained sections of basal cell adenocarcinoma. (A) Basaloid cells arranged in a trabecular aspect. Within the trabecules small lumens or pseudocystic lumens are evident, as well as squamous metaplasia (×92). (B) Two foci of squamous metaplasia are seen within the blocks of basaloid cells (×92). (C) Cribriform aspect of the tumour. Observe a mitosis (arrowhead) at right bottom (×294). (D) Tumour cells are seen surrounding a nerve structure (asterisk) (×92). 

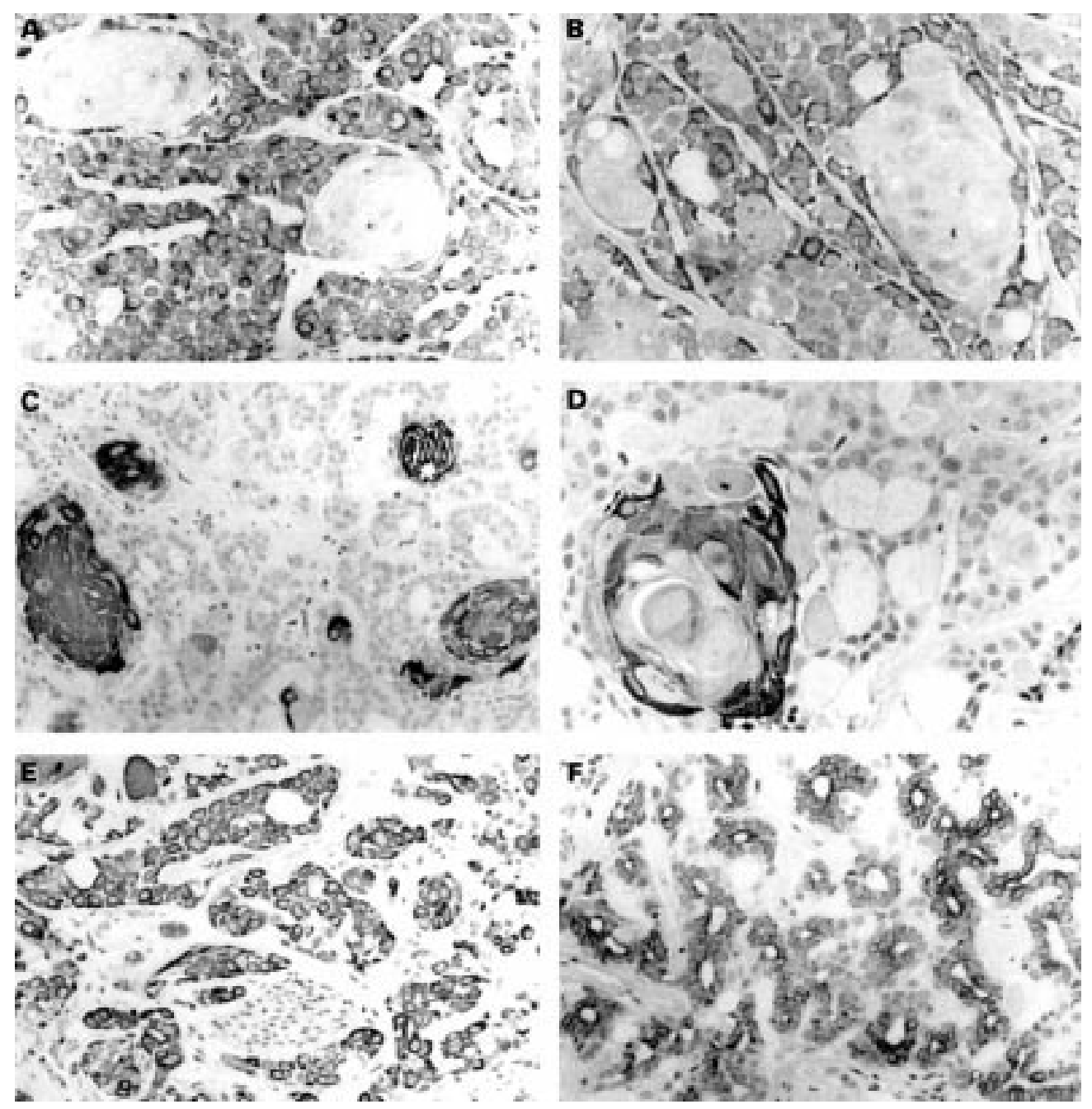

Figure 2 Immunophenotype of basal cell adenocarcinoma (streptavidin-biotin method). (A) Vimentin is expressed by most of the tumour cells, except for squamous areas $(\times 184)$. (B) Actin strongly stains cells at the periphery of squamous cells (×184). (C) Cytokeratin (CK) 13 is expressed in squamous metaplasia areas ( $\times 92)$. (D) CK19 in peripheral cells of squamous metaplasia $(\times 184)$. (E) Immunostaining of CK 14 in tumour cells involving a peripheral nerve $(\times 92)$. (F) Expression of CK 7 in luminal cells of ductal structures $(\times 92)$.

such among the low grade malignancies in the latest World Health Organisation classification. $^{2}$

Most basal cell adenocarcinomas have been reported to occur in major glands. ${ }^{134}$ The average age of patients is 60 years, ranging from two months to 92 years. There is a slight prevalence of males. In minor salivary glands basal cell adenocarcinomas are even more rare, as only three cases have been reported on the palate and one on the lip..$^{5-8}$

The few published reports that have dealt with the immunohistochemical aspects of basal cell adenocarcinoma have shown positivity of tumour cells for cytokeratins (AE1/AE3), smooth muscle actin, and epithelial membrane antigen, ${ }^{9-12}$ and positivity ${ }^{5-12}$ or negativity ${ }^{11}$ for S-100 protein, vimentin, and carcinoembryonic antigen. Ultrastructurally one study showed the presence of cells containing intracytoplasmic secretion, but no myoepithelial cells. ${ }^{10}$ In another study, some cells with characteristics of myoepithelial cells were seen. ${ }^{11}$

Some investigators have also studied cell proliferation markers, apoptosis, p53, bcl-2, and epidermal growth factors in basal cell adenocarcinoma, and positivity for p53 and bcl-2 has been shown in about half the cases. $^{11} 1314$

Owing to the paucity of reported cases of basal cell adenocarcinoma, especially those from minor glands, our purpose in this report is to describe the clinical, histological, and immunohistochemical features of a case of basal cell adenocarcinoma arising in the palate.

\section{Methods}

A 24 year old white woman was seen in July 1994 at a Public Hospital in São Paulo, with a complaint of a swelling involving the soft and hard palate. Intraoral examination revealed a 3 $\mathrm{cm}$ painless, firm, nodular mass with well defined borders and normal overlying mucosa. No neck masses or palpable lymph nodes were noticed. The patient was otherwise in good health. The clinical impression was that this was a salivary gland tumour. Computed tomography revealed minimal alteration in osseous thickness in the right palate, and no relation to the dental roots. The lesion was excised and the specimen was sent to the oral 
pathology department of the University of São Paulo. After a diagnosis of basal cell adenocarcinoma was made the patient underwent further surgery, and the excision was extended until surgical margins were free of tumour. The postoperative period was uneventful and a follow up of almost five years has shown no evidence of recurrence.

Biopsy material obtained at the surgery was fixed in $10 \%$ neutral formalin for 24 hours, embedded in paraffin, and $5 \mu \mathrm{m}$ sections cut for haematoxylin and eosin (H\&E) stain. For immunohistochemical reactions, $3 \mu \mathrm{m}$ sections were obtained and processed by the streptavidin-biotin method. The antibodies used, with their concentrations, time of incubation and suppliers, are listed in table 1 . Before reaction with cytokeratins, the sections were treated in a microwave oven for antigen retrieval using three 5 minute baths at $700 \mathrm{~W}$, with the slides immersed in citric acid $(10 \mathrm{mM}$, $\mathrm{pH}$ 6.0). Diaminobenzidine was used as the chromogen, and the slides were counterstained with Mayer's haematoxylin. Appropriate positive and negative controls were included.

\section{Results}

Histologically the tumour consisted of an uncapsulated mass composed of uniform basaloid cells showing oval or round nuclei and usually one prominent central or peripheral nucleolus. These cells were arranged in small solid islands or cords, sometimes showing a duct lumen, and when the cords anastomosed, a cribriform pattern was seen. Squamous metaplasia was a conspicuous finding, present in all the arrangements, sometimes forming extensive areas. Individual keratinising cells were also seen. The tumour invaded the adjacent epithelium and salivary gland tissue. Neural invasion was a frequent finding. Mitosis was rarely seen. Neutrophils and lymphocytes were present, scattered in the tumour (fig 1, A-D).

Immunohistochemical reactions indicated that vimentin was expressed by most of the tumour cells, except for luminal cells in the ductal structures and in areas of squamous metaplasia. Actin was positive in the outer cells of the ductal structures and in cells of the cords and cribriform arrangements. Cytokeratin (CK) 14 was present in all of the tumour cells. CK 7 and CK 19 were present in luminal cells of duct-like structures and also in a few cells present in the vicinity of squamous metaplasia areas; CK 8 and CK 18 were expressed only in luminal cells of duct-like structures. In areas of squamous metaplasia the cells were positive to CK 13, CK14, and also CK19 in the peripheral region (fig 2, A-F). Laminin was positive as a thin line around the arrangements and sometimes inside pseudocystic spaces and in the walls of vessels present in the stroma.

\section{Discussion}

The tumour in this case was composed of relatively uniform monotonous basaloid cells distributed mainly in a cribriform pattern, with infiltrative growth and perineural invasion. In addition, the tumour showed squamous metaplasia as a conspicuous characteristic.

Immunohistochemical staining revealed a profile similar to that seen in intercalated duct derived tumours, with the presence of myoepithelial tumour cells characterised by vimentin, muscle specific actin, and CK14. Luminal cells of intercalated duct origin, characterised by the positivity for cytokeratins $7,8,18$, and 19 , were not often seen. It seems that these elements were the ones that underwent squamous metaplasia, as the myoepithelial cells were apposed to areas of squamous metaplasia.

The differential diagnosis includes other tumours in which basal cells are the main cellular component: basaloid squamous cell carcinoma, adenoid cystic carcinoma, and basal cell adenoma. Fusion of the tumour with the overlying epithelium was present, so a diagnosis of basaloid squamous cell carcinoma was considered. However, this was excluded on the basis that there was no associated squamous cell carcinoma or carcinoma in situ. ${ }^{15}$ The cribriform pattern and the positivity of most cells for actin reinforced this decision.

Among tumours that are composed mainly of basaloid cells and share the immunohistochemical intercalated duct profile are adenoid cystic carcinoma and basal cell adenoma. As these tumours mimic the intercalated duct, it is to be expected that they would have features in common. ${ }^{16}$ Adenoid cystic carcinoma was considered as a possible diagnosis in this case. However, the cytological features of the tumour, especially the large pale cells with oval and clear nuclei, are different from the hyperchromatic and angular nuclei usually seen in adenoid cystic carcinoma cells. ${ }^{4}$ In addition, the positivity of most cells for cytokeratin 14 is not found in adenoid cystic carcinoma, where only duct luminal cells are positive. Myoepithelial cells positive to cytokeratin 14 are only occasionally present in the tubular type of adenoid cystic carcinoma. ${ }^{17}$

Squamous metaplasia has occasionally been observed in pleomorphic adenoma and basal cell adenoma and adenocarcinoma. Moreover, it has been reported in an isolated case of myoepithelioma composed of clear cells ${ }^{18}$ and also in a case of adenoid cystic carcinoma. ${ }^{19}$ However in this latter case, even the authors were not convinced of the diagnosis.

Basal cell adenocarcinoma and adenoid cystic carcinoma may produce a hyalinised, eosinophilic basal lamina, but in basal cell adenocarcinoma it is more striking in the membranous type. ${ }^{20}$ In the present case, reaction with laminin showed a discrete positivity around duct-like structures and in the lumen of pseudocysts. In adenoid cystic carcinoma, laminin is seen as a thick line in the lumen and around pseudocysts. ${ }^{21}$

As stated in published reports, basal cell adenoma is differentiated from basal cell adenocarcinomas mainly by the invasive growth of the latter. Ellis and Wiscovitch ${ }^{1}$ define basal cell adenocarcinomas as tumours having the cytomorphological features of basal cell adenomas, but with growth characteristics of a malignant neoplasm. In the present case, 
neural invasion and glandular invasion were readily observed.

On the basis of the considerations outlined above, and the fact that squamous metaplasia is a feature of basal cell adenomas, we considered this tumour to be a basal cell adenocarcinoma. Owing to the rarity of the lesion, a prognosis cannot be given. In the present case, the patient is being followed up, and five years after surgery she is very well, without any signs of tumour recurrence.

1 Ellis GL, Wiscovitch JG. Basal cell adenocarcinomas of the major salivary glands. Oral Surg Oral Med Oral Pathol 1990;69:461-9.

2 Seifert G. World Health Organisation histological classification of tumours. Histological typing of salivary gland tumour, $2 \mathrm{nd}$ ed. Berlin: Springer, 1991

3 Dardick I. Color atlas/text of salivary gland tumor pathology. New York: Igaku-Shoin, 1996.

4 Ellis GL, Auclair PL. Atlas of tumour pathology. Tumours of the salivary glands. Washington, DC: Armed Forces Institute of Pathology, 1996.

5 Lo AK, Topf JS, Jackson IT, et al. Minor salivary gland basal cell adenocarcinoma of the palate. F Oral Maxillofac Surg 1992;50:531-4.

6 Fonseca I, Soares J. Basal cell adenocarcinoma of minor salivary and seromucous glands of the head and neck salivary and seromucous glands of the heac
region. Semin Diagn Pathol 1996;13:128-37.

7 Plath T, Dallenbach. Basal cell adenocarcinoma of the minor salivary glands of the palate. Case report and review of the literature. Mund-, Kiefer- und Gesichtschirurgie 1998; 2:275-8.

8 Antonescu CR, Terzakis JA. Multiple malignant cylindromas of skin in association with basal cell adenocarcinoma with adenoid cystic features of minor salivary gland. $\mathcal{F}$ Cutan Pathol 1997;24:449-53.

9 Williams SB, Ellis GL, Auclair PL. Immunohistochemical Oral Pathol 1993;75:64-9.
10 Raslan WF, Leonetti JP, Sawyer DR. Basal cell adenocarcinoma of the parotid gland: a case report with immuno-
histochemical, ultrastructural findings and review of the lithistochemical, ultrastructural findings and review
erature. F Oral Maxillofac Surg 1995;53:1457-62.

11 Quddus MR, Henley JD, Affify AM, et al. Basal cell adenocarcinoma of the salivary gland. An ultrastructural and immunohistochemical study. Oral Surg Oral Med Oral Pathol Oral Radiol Endod 1999;87:485-92.

12 Kim KI, Oh HE, Mun JS, et al. Basal cell adenocarcinoma of the salivary gland-a case report. 7 Korean Med $S c i$ 1997;12:461-4

13 Rosa JC, Félix A, Fonseca I, et al. Immunoexpression of c-erbB-2 and p53 in benign and malignant salivary neoplasms with myoepithelial differentiation. Clin Pathol 1997;50:661-3.

14 Nagao T, Sugano I, Ishida Y, et al. Basal cell adenocarcinoma of the salivary glands. Comparison with basal cell adenoma through assessment of cell proliferation, apoptoadenoma through assessment of cell proliferation, apopto-
sis, and expression of p53 and bcl-2. Cancer 1998;82:43947 .

15 Araújo VC, Biazolla ER, Moraes NP, et al. Basaloid squamous carcinoma of the oral cavity. Report of a case. Oral Surg Oral Med Oral Pathol 1993;76:622-5.

16 Grenko RT, Abendroth CS, Davis AT, et al. Hybrid tumours or salivary gland tumours sharing common differentiation pathways? Reexamining adenoid cystic and epithelialmyoepithelial carcinomas. Oral Surg Oral Med Oral Pathol Oral Radiol/Endod 1998;86:188-95.

17 Araújo VC, Sousa SOM. Expression of different keratins in salivary gland tumours. Oral Oncol Eur f Cancer 1996;32B: 14-18.

18 Michal M, Skalova A, Simpson RHW, et al. Clear cell malignant myoepithelioma of the salivary glands. Histopathology 1996,28:309-15.

19 Wal van der JE, Snow GB, Karim ABMF, et al. Adenoid cystic carcinoma of the palate with squamous metaplasia or basaloid-squamous carcinoma? Report of a case. 7 Oral Pathol Med 1994;23:461-4.

20 Yu GY, Ubmuller J, Donath K. Membranous basal cell adenoma of the salivary gland: a clinicopathologic study of 12 cases. Acta Otolaryngol (Stockh) 1998,118:588-93.

21 Cheng J, Saku T, Okabe H, et al. Basement membranes in adenoid cystic carcinoma. An immunohistochemical study. Cancer 1991;69:2631-40. 